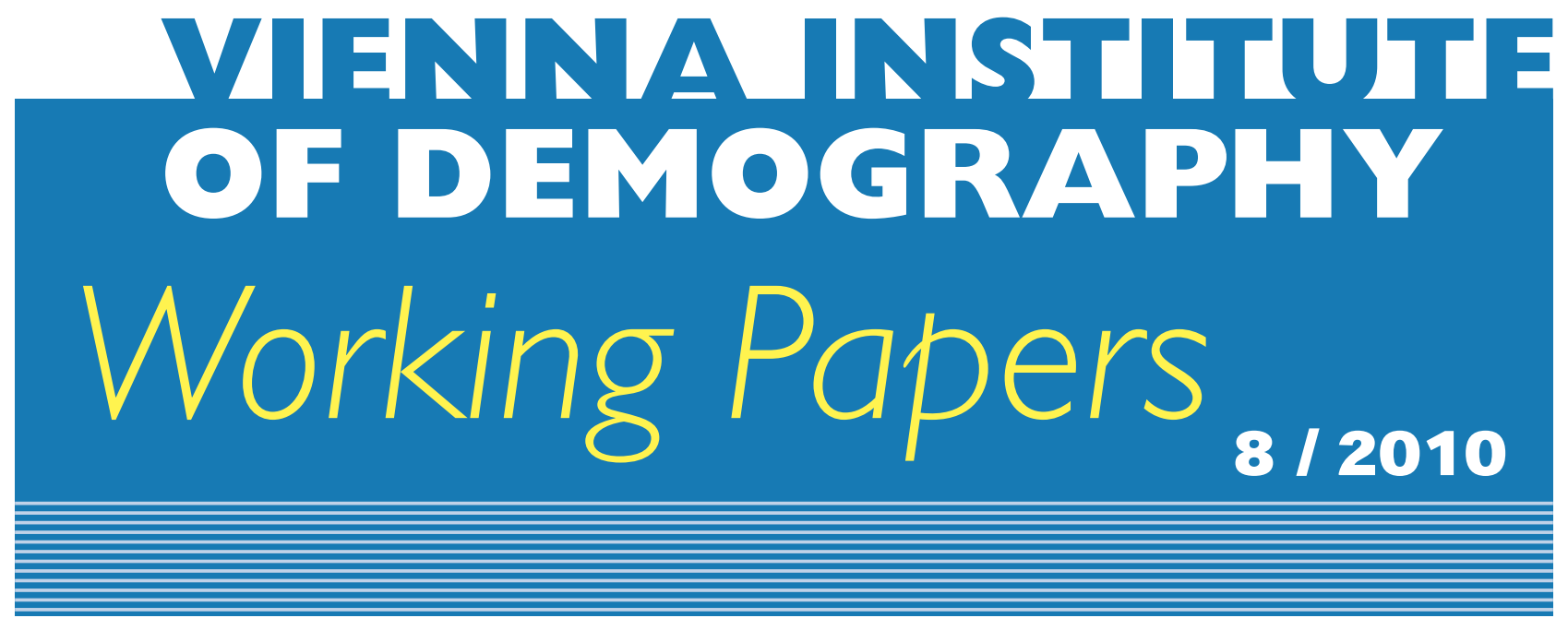

Klaus Prettner and Alexia Prskawetz

\title{
Demographic Change in Models of Endogenous Economic Growth. A Survey.
}

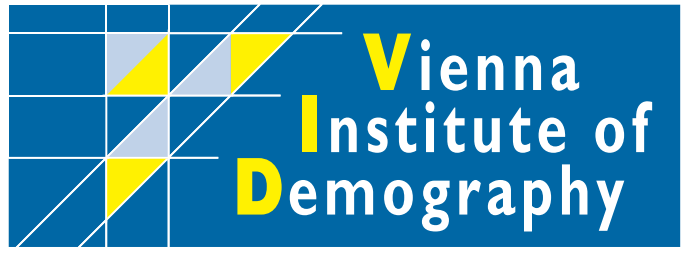

Vienna Institute of Demography Austrian Academy of Sciences

Wohllebengasse 12-14

A-I040Vienna $\cdot$ Austria

E-Mail:vid@oeaw.ac.at

Website:www.oeaw.ac.at/vid 


\begin{abstract}
The purpose of this article is to identify the role of population size, population growth and population ageing in models of endogenous economic growth. While in exogenous growth models demographic variables are linked to economic prosperity mainly via the population size, the structure of the workforce, and the capital intensity of workers, endogenous growth models and their successors also allow for interrelationships between demography and technological change. However, most of the existing literature considers only the interrelationships based on population size and its growth rate and does not explicitly account for population ageing. The aim of this paper is (a) to review the role of population size and population growth in the most commonly used economic growth models (with a focus on endogenous economic growth models), (b) discuss models that also allow for population ageing, and (c) sketch out the policy implications of the most commonly used endogenous growth models and compare them to each other.
\end{abstract}

JEL classification: J10, O16, O41

\title{
Keywords
}

Demographic change, endogenous $R \& D$, economic growth

\section{Authors}

Klaus Prettner, Vienna Institute of Demography, Austrian Academy of Sciences, and Institute of Mathematical Methods in Economics, Vienna University of Technology; email: klaus.prettner@oeaw.ac.at

Alexia Prskawetz, Institute of Mathematical Methods in Economics (research group on economics), Vienna University of Technology, and Vienna Institute of Demography, Austrian Academy of Sciences; email: afp@econ.tuwien.ac.at

\section{Acknowledgments}

We would like to thank Holger Strulik (University of Hannover) and three anonymous referees for valuable comments and suggestions. The paper was prepared within the research project "Agglomeration processes in ageing societies" funded by the Vienna Science and Technology Fund (WWTF) in its "Mathematics and..." Call 2007. 


\title{
Demographic Change in Models of Endogenous Economic Growth. A Survey.
}

\author{
Klaus Prettner and Alexia Prskawetz
}

\section{Introduction}

During the last decades, all industrialized countries had to face declines in birth rates (even far below the replacement level), while survival rates continued to improve (in particular for older cohorts), allowing people to reach older ages. As a consequence, populations in industrialized countries started to age and eventually - as declining mortality rates and migration are not able to compensate the fall in fertility - they will even decline (see for example United Nations, 2007; Eurostat, 2009). While these developments will happen for sure, it is not clear, how they will affect the overall economic performance of the countries under consideration. The interrelations between long-run economic growth on the one hand and the population size, its growth rate as well as population ageing on the other hand are therefore of central interest (see for example Bloom et al., 2008, 2010).

To gain insight into the linkage between demography and economic performance, we review different models explaining medium-run (corresponding to the transitional path) and long-run (corresponding to the steady-state equilibrium or the balanced growth path) economic growth and discuss their predictions when the underlying demographic structure is changed. The results crucially depend on the models used for analysing the medium- and the long-run economic growth developments. In exogenous growth models demographic variables are linked to economic growth via population size, the structure of the workforce and the capital intensity of workers. An increase in population size will foster capital dilution, while changes in the decomposition of the workforce will affect aggregate productivity.

Endogenous growth models allow for additional channels through which demographic changes can affect the overall economic performance. These include the role of the number of scientists determining the pace of technological change, changes in the demand for innovative goods as well as changes in the human capital endowment and therefore the productivity of workers.

Semi-endogenous growth models have been mainly designed to get rid of the positive relation between population size and economic growth (scale effect) as evident in endogenous growth models of the first generation since such an effect is not supported by empirical evidence (cf. Jones, 1995). However, this extension has come at the price that economic development again depends on exogenously given parameter values and long-run growth cannot be affected by economic policy. This is a feature that this type of growth models shares with exogenous growth models which is also the reason why they are called semi-endogenous. 
Therefore Peretto (1998) paved the way for another type of scale free endogenous growth models, where the policy interventions are effective. Nevertheless, another shortcoming of most scale free endogenous growth models still exists because they predict a positive relationship between population growth and per capita output growth, which cannot be observed in empirical studies (cf. Brander and Dowrick, 1994; Kelley and Schmidt, 1995). Recent attempts in modelling longrun economic growth by Dalgaard and Kreiner (2001) and Strulik (2005) have addressed this issue and their models allow a negative correlation between population growth and per capita output growth.

The aim of our paper is to provide an overview of the effects that can arise from varying the population size, its growth rate and its age structure on per capita output growth in selected endogenous growth models. Generally, our purpose is to give a short and concise description of the underlying models' features with respect to medium-run as well as with respect to long-run (steady state) growth and to assess its interrelations with the demographic variables. Furthermore, we aim to point out policy implications that these different models offer.

Our paper complements Gruescu (2007) who concentrates on the Solow (1956) and the Lucas (1988) frameworks and also provides a short overview regarding the sensitivity of endogenous and semi-endogenous growth models with respect to changes in the size and the growth rate of the population.

In section 2, we briefly consider models with exogenous technological change and discuss their shortcomings. In section 3 we review selected models of endogenous growth and their extensions to also include population ageing. In section 4 we present selected semi-endogenous growth models, while in section 5 we review models that integrate horizontal and vertical innovations. Section 6 summarizes the results and draws some conclusions.

\section{Exogenous Growth Models}

The first framework suited to study long-run economic growth was the Solow (1956) model, augmented with exogenous technological change. Aggregate output in this case can be written as

$$
Y=K^{\alpha}(L A)^{1-\alpha}
$$

where $Y$ refers to total output, $L$ is the amount of employed labour which is equivalent to the population size due to assumption of full employment ${ }^{1}, A$ denotes labour augmenting technology and $\alpha$ is the capital share of final output. Rewriting this expression in terms of per capita output $y$ and obtaining the growth rate of the resulting expression leads to

$$
g_{y}=\alpha\left[s k^{\alpha-1} A^{1-\alpha}-(n+\delta)\right]+(1-\alpha) g_{A},
$$

where $g_{y}$ denotes the per capita rate of economic growth, $s$ refers to the exogenously given savings rate, $n$ to the rate of population growth, $\delta$ represents the rate of physical capital depreciation and $g_{A}$ is the rate of technological growth. Obviously, population size does not effect long-run economic growth in the Solow model. However, during the adjustment to the new steady state, population growth, i.e. increases in $n$, will slow down per capita output growth, since the capital intensity of workers decreases. In the steady state, the term in brackets pins down to the growth rate of $A$

\footnotetext{
${ }^{1}$ In most of the models presented here the population size is assumed to be equivalent to the labour force. If this is not the case, we will mention it explicitly.
} 
(see Gruescu, 2007, p. 51) and so does per capita output

$$
g_{y}^{*}=g_{A},
$$

where an asterisk denotes steady state growth rates from now on. This implies that changes in the population growth rate do not affect per capita output growth in the long-run. The simple structure of the Solow (1956) model implies that (a) population ageing cannot be analysed because there is no heterogeneity between individuals with respect to age and (b) governmental interventions are ineffective because of the exogeneity of the central parameters $g_{A}, n$ and $s$.

Gruescu (2007) introduces population ageing into the Solow (1956) model by distinguishing between workers and retirees. She introduces the dependency ratio $D=\frac{N-L}{L}$ where $N$ refers to the population size and $L$ to the size of the workforce. Per capita output growth can then be written as

$$
g_{y}=\alpha\left[s k^{\alpha-1} A^{1-\alpha}(1+D)^{-(1-\alpha)}-(n+\delta)\right]-(1-\alpha) g_{(1+D)}+(1-\alpha) g_{A},
$$

where $g_{(1+D)}$ refers to the growth rate of the dependency ratio. Compared to equation (2), now also the composition of the population affects per capita output growth via two channels. The first effect, denoted by the term $(1+D)^{-(1-\alpha)}$, captures the fact that a high dependency ratio increases the number of dissaving individuals and therefore leads to a decrease in the capital intensity of workers which reduces per capita output growth during the transition period. The second effect, denoted by the term $-(1-\alpha) g_{(1+D)}$, captures the fact that an increase in the dependency ratio implies fewer workers in the production process and hence diminishes the growth rate of output.

While the population size still does not matter, an increase in the population growth rate has two opposing effects. On the one hand it reduces the capital intensity of workers but on the other hand it decreases the dependency ratio. To summarize, in the medium run, an increase in the dependency ratio negatively impacts upon economic growth, whereas the effects of changes in the population growth rate are ambiguous.

In the steady state, Gruescu (2007) shows that per capita output growth pins down to

$$
g_{y}^{*}=g_{A}-(1-\alpha) g_{1+D}
$$

implying that population ageing negatively affects long-run economic growth ${ }^{2}$. This contrasts to the traditional finding of the Solow (1956) model that long-run per capita growth is entirely driven by technological progress. Therefore policy-makers could intervene by implementing the growth enhancing policy of increasing the retirement age and thus to slow down or even revert $g_{1+D}$.

There have been a lot of different attempts to extend the basic Solow (1956) model for example by Cass (1965) and Koopmans (1965) which build on Ramsey (1928) and endogenize the savings rate. However, these models are not suited to study demographic aspects because they rely on the assumption that there is one single representative individual whose decisions determine the consumer side of the economy. Altogether the basic conclusions of the Solow (1956) model with respect to medium- and long-run economic growth carry over to these types of models. Blanchard (1985) and Yaari (1965) replace the representative agent setting by introducing an overlapping generations (OLG) structure and thereby age specific heterogeneity of individuals. Blanchard

\footnotetext{
${ }^{2}$ However, the assumption that the dependency ratio grows at a constant rate in the steady state might not be sensible because the upper bound of the dependency ratio is one and the lower bound is zero.
} 
(1985) shows that in the corresponding model population ageing affects the demand side of the economy by slowing down aggregate consumption expenditure growth and thereby in equilibrium also per capita output growth. However, the central results of the Ramsey (1928) and Solow (1956) models are still valid. Several attempts have been made to introduce more realistic demographic structures and life-cycle details (such as varying propensities to consume, work, save, etc. across age) into OLG models (see Horvath, 2007, for an excellent review). Age-dependent mortality is introduced by Bommier and Lee (2003) and Li and Tuljapurkar (2004). The latter focuses in particular on modelling the distribution function of age at death thereby taking into account the reduction of the variance in the age at death over time. As shown in Horvath (2007), introducing age-dependent lifetime uncertainty mainly influences capital accumulation, consumption behaviour and the discount rate on future labour income. Increasing risk of death with age negatively affects capital accumulation and increases the discount rate on future labour income. Since capital accumulation is the driving force of economic development in exogenous growth models, this leads to a slowdown of economic growth. More realistic mortality patterns in the Blanchard (1985) framework have recently been studied by Heijdra and Romp (2006), Heijdra and Romp (2007) and d'Albis (2007) (see also Heijdra (2009) chapter 16 for some of these citations).

The workhorse model in discrete time as opposed to the continuous time formulation of Blanchard is the OLG model of Diamond (1965) based on previous work by Samuelson (1958). Individuals are assumed to live for two time periods. In the first period of life they inelastically supply one unit of labour, save and consume while in the second period of life they only consume and earn returns on their first period savings. The consumption good is produced by competitive firms whose output is determined by the capital stock (i.e. aggregate savings) and the labour supply. The Diamond model has been applied to study population ageing and its macroeconomic consequences including the research on pension systems and endogenous human capital investments. See Heijdra (2009) chapter 17 for a review and potential applications of the Diamond-Samuelson model. Altogether, policies which slow down physical capital- and human capital accumulation, also exhibit negative impacts on economic prosperity in terms of per capita output growth. However, as Bommier and Lee (2003) argue, a two generations model misses the fact that life starts and ends with a period of dependency. An extension to several life stages is allowed for in the probabilistic ageing model of Grafenhofer et al. (2006), while large scale computable OLG models typically assume a duration single years for each period of life (cf. Auerbach and Kotlikoff, 1987). Another extension of the basic Diamond (1965) model was implemented by Prettner and Prskawetz (2010), who introduce endogenous human capital accumulation via a quality-quantity trade-off effect (Becker, 1960) as well as imperfect substitutability between workers of different age in the production process. The quality-quantity trade-off effect states that individuals can either invest into number of children (quantity) which fosters population growth, or into education of their children (quality) which slows down population growth but increases per capita human capital. The model is used to study the implications of decreasing fertility, which is equivalent to population ageing, on medium- and long-run economic growth. The basic result of exogenous growth models namely that faster population growth leads to capital dilution and hence slows down economic growth carries over to this model, while the slowdown of economic growth is reinforced by the negative effect of faster population growth on human capital accumulation. 


\section{Endogenous Growth Models}

\subsection{Models with Increasing Returns to Capital}

One of the first attempts to endogenize long-run economic growth was undertaken by Romer (1986). He introduces firm specific knowledge as a production factor. There is learning by doing in the sense that employing capital is assumed to have positive intertemporal knowledge spillovers such that there are increasing returns to scale with respect to the per capita stock of physical capital in the aggregate production function. Altogether this ensures that long-run per capita output growth is possible without relying on exogenous technological change. However, this specification is equivalent to one having increasing returns to scale with respect to the capital stock, which has been one of the main critiques regarding the Romer (1986) model.

The central result of the model is that in equilibrium the stock of knowledge grows without bound and so does per capita output. If the number of agents increases, the stock of knowledge would also increase and growth would be fostered. This points out that demography - as represented by population size - is positively related to long-run economic growth. However, population growth is not allowed for and the age structure of the population is not considered.

Policy-makers are able to intervene in the Romer (1986) framework by implementing policies that increase capital (which is equivalent to knowledge) accumulation. However, it is hard to imagine how such policies would have to be designed because it is usually an increase in longevity which triggers human capital investments and the age structure of the population is not specified in the Romer (1986) framework due to the representative agent setting.

Futagami and Nakajima (2001) investigate the effects of population ageing via introducing life cycle savings decisions into the Romer (1986) framework ${ }^{3}$. Additionally, they assume that individuals live for two periods: In the first period they have to work and earn wages, whereas in the second period they are retired and can only consume out of their savings carried over from the previous period. Via dynamically optimizing households, Futagami and Nakajima (2001) derive an expression for the steady state growth rate of the economy, $g^{*},{ }^{4}$ depending on longevity, $T$, the interest rate, $r$, the parameters $\rho$ and $\theta$, describing the discount rate and the retirement age respectively, and the technological level of the economy, $A$ :

$$
g^{*}=A-\alpha A\left[\frac{\rho}{1-e^{-\rho T}} \frac{1-e^{-(r-g)} \theta}{(r-g) \theta} \frac{\left(e^{(r-g-\rho) T}-1\right)}{r-g-\rho}\right] .
$$

Since the growth rate of population is set equal to zero, the growth rate of per capita output coincides with the growth rate of total output. We denote such a growth rate by $g$ without any subscript from now on. Implicitly differentiating equation (6) with respect to longevity yields

$$
\frac{d g^{*}}{d T}=\frac{A \partial s\left(g^{*} ; T\right) / \partial T}{1-A \partial s\left(g^{*} ; T\right) / \partial g^{*}},
$$

where Futagami and Nakajima (2001) show that, evaluated in equilibrium, the numerator as well as the denominator are negative. Consequently, the growth rate of aggregate output increases as longevity rises. The explanation is that an increase in $T$ is associated with a longer retirement period, therefore people would have to save more during their working life to afford consumption,

\footnotetext{
${ }^{3}$ To be precise, Futagami and Nakajima (2001) consider the capital stock instead of the stock of knowledge to be associated with increasing returns to scale in the aggregate production function.

${ }^{4}$ Note that in Romer (1986), on which Futagami and Nakajima (2001) is based, there are no transitional dynamics.
} 
when old. Since the production function exhibits increasing returns to scale with respect to the capital stock, the increase in savings promotes output growth.

Regarding the growth-related effects of demographic change, the results carry over from the Romer (1986) model. An interesting feature of the model by Futagami and Nakajima (2001) is, however, that a rise in the retirement age would slow down economic growth. The intuition behind this result is straightforward: As the retirement period of individuals gets shorter, they will have to save less in order to afford consumption when old. This in turn decreases capital accumulation and hence economic growth. However, the result crucially hinges on the fact that the Romer (1986) model has been used as a basis for the analysis. If the Romer (1990) is used instead, this result would have changed (see below). Therefore the policy implication of reducing the retirement age to foster growth, although valid in this particular model, has to be interpreted with caution.

There also have been attempts to introduce an OLG structure according to Blanchard (1985) into the model of Romer (1986) by Alogoskoufis and van der Ploeg (1990) and Saint-Paul (1992). The result is that the presence of overlapping generations slows down economic growth because it negatively affects capital accumulation (see also Heijdra, 2009, chapter 16.4.3).

\subsection{Human Capital Models}

An alternative framework that allows for endogenous economic growth was proposed by Lucas (1988) focusing on human capital accumulation as the engine of growth. Human capital at the individual level is broadly defined as the general skill level $h(t)$. Total human capital $H(t)=$ $h(t) L(t)$ (where $\mathrm{L}$ indicates the size of the labour force) is assumed to follow a linear technology that depends on the time spent in education, $1-u(t)$, the current educational technology, $E$, and a depreciation factor, $\delta$ :

$$
\dot{H}=E(1-u) H-\delta H
$$

The remaining time $u(t)$ people spend in the production of the final output $Y$ which is produced with capital $K$ and effective labour $H_{e}=u H$ defined as the skill weighted hours of work in production. As shown in (Gruescu, 2007, p.81), assuming a CES utility function with an intertemporal elasticity of substitution equal to $\frac{1}{\sigma}$ and a discount rate equal to $\rho$ to describe individual consumption as well as a Cobb Douglas type aggregate production function, the steady state growth rate of per capita output is given by

$$
g_{y}^{*}=\frac{1}{\sigma}(E-\delta-\rho+n)
$$

It follows that income per capita is positively associated with educational productivity E. Obviously, the lower the population growth rate the higher educational productivity needs to be in order to allow for positive per capita income growth. Increasing educational productivity may therefore be seen as a policy tool to sustain economic growth under conditions of population decline.

Similar as for the Solow model, Gruescu (Gruescu, 2007, p. 108ff) also introduces population ageing into the Lucas model via modelling the dependency ratio $D=\frac{N-L}{L}$. The steady growth rate of per capita output changes to

$$
g_{y}^{*}=\frac{1}{\sigma}\left(E-\delta-\rho+n-g_{(1+D)}\right)
$$


where $g_{1+D}$ again refers to the growth rate of the dependency ratio. The comparison to (9) shows that an increase in the dependency ratio - as it will occur as a result of population ageing depresses economic growth. As shown in Gruescu (Gruescu, 2007, p. 116f), when the growth rate of the dependency ratio is positive, more time is spent in education and less time in production. Intuitively, people try to counteract the negative effect of ageing on economic growth by investing more in education in order to increase future consumption and income.

More detailed demographic structures have recently been introduced in models of human capital by e.g. de la Croix and Licandro (1999). Instead of assuming a continuous investment into education over the whole life, the authors more realistically assume that agents decide on the length of schooling before starting work. The steady state growth rate is shown to first increase and then decrease with increasing life expectancy. I.e. for countries with low life expectancy the relation between economic growth and life expectancy is positive but may turn negative for advanced countries with high life expectancy. An extension of this model is presented in Boucekkine et al. (2002) where changes in longevity and fertility are investigated.

\subsection{Horizontal Innovations}

Starting with the Romer (1990) model, technological change as the main driving force behind economic growth, has been endogenized. Technological improvements are considered as increases in the overall amount of different varieties that can be produced, i.e. the amount of blueprints discovered in the $\mathrm{R} \& \mathrm{D}$ sector of the economy. This type of technological progress is referred to as horizontal innovation. Aggregate output is produced with labour and intermediate goods according to the production function

$$
Y=L_{Y}^{\alpha} \int_{0}^{A} x_{i}^{1-\alpha} d i
$$

where $L_{Y}$ refers to workers employed in the final goods sector, $x$ is the amount of a certain variety $i \in \mathbb{R}$ used as intermediate input in final goods production, $A$ again refers to the technological frontier which now evolves endogenously and $1-\alpha$ is the intermediate share of output. It is easily seen that a growing technological frontier is the central driving force behind long-run economic growth. It's behaviour over time is characterized by the differential equation

$$
\dot{A}=\delta L_{A} A
$$

where $\delta$ represents productivity of researchers, and $L_{A}$ is the amount of workers employed in the $\mathrm{R} \& \mathrm{D}$ sector $^{5}$ which can also be referred to as scientists. This equation ensures that there are no diminishing returns to scale with respect to the production of new ideas. To put it differently, an increase in $A$ contributes to the productivity of researchers such that the development of new blueprints does not become ever more complex. With these ingredients, Romer (1990) derives the following expression for the growth rate of an economy

$$
g^{*}=\frac{\delta L(1-\alpha)-\rho}{\sigma+(1-\alpha)},
$$

\footnotetext{
${ }^{5}$ We see that the growth rate of technology is constant if the amount of labour in R \& D production stays constant as well.
} 
where $L=L_{Y}+L_{A}$ is the total labour force, $\rho$ represents the time preference rate of individuals and $\sigma$ denotes the inverse of the intertemporal elasticity of substitution in an individual's utility function. This equation states that the growth rate of the economy positively depends on the productivity of researchers, the patience of individuals, and the population size. In order to come up with a balanced growth path where all variables grow at a constant rate, Romer (1990) assumes that the population size $L$ is fixed. The positive relation between the per capita growth rate of the economy and the population size is called "scale effect", which is present in all these types of endogenous growth models. The age structure of the population is not considered in the Romer (1990) framework.

Abstracting from market structure considerations, policy-makers have different opportunities to intervene because subsidies for savings or for the use of intermediate inputs have growth effects rather than level effects as in exogenous growth models. The most important opportunity to intervene in order to speed up long-run economic growth is to subsidize R\&D. This would increase wages for scientists such that the corresponding sector could attract more workers and due to equation (12) produce more blueprints.

Futagami et al. (2002) use the Romer (1990) model as a basic framework for analysing the growth effects of increasing longevity. In contrast to Futagami and Nakajima (2001), which use the Romer (1986) model as starting point, technological change is endogenously determined in this setup. Due to the complexity of the expression for per capita growth, $g$, there are no clear implications on its reaction in response to demographic change. The derivatives of $g$ with respect to longevity, $T$, and the retirement age, $\theta$, lead to expressions with ambiguous sign. If one wants to analyse demographic aspects more thoroughly in this context, the model would have to be simplified considerably. However, two implications of Futagami et al. (2002) are worth mentioning since they contrast the results of Futagami and Nakajima (2001). First, increases in longevity are not necessarily associated with rising growth rates and second, increases in the retirement age $\theta$ may not harm long-run economic growth perspectives. The intuition for this result is that the Romer (1990) model, on which Futagami et al. (2002) rely, emphasized the crucial role of the size of the labour force on economic growth. Since increases in longevity mainly increase the number of retirees, its effects on economic growth are therefore limited, while raising the retirement age increases the labour force and thereby countervails the negative effect of lower aggregate savings also triggered by the rise in the retirement age.

Prettner (2009) abandons the representative agent assumption of the Romer (1990) model and introduces an OLG structure according to Blanchard (1985). Each individual has to face a constant age independent risk of death which, due to the law of large numbers, corresponds to the fraction of individuals dying at each instant. The birth rate is assumed to be equal to the death rate such that population growth is ruled out in order to be consistent with the Romer (1990) approach. However, changing the mortality rate and thereby also the birth rate leads to a shift in the age structure of the population and allows to analyse the effects of population ageing on economic growth. The following expression for the steady state per capita growth rate is derived

$$
g^{*}=\frac{\lambda L \alpha-\rho-\mu \Omega \sigma}{\alpha+\sigma}
$$

where $\lambda$ denotes the productivity of researchers, $L$ is the labour force, $\alpha$ refers to the intermediate input share in final goods production, $\rho$ is the rate of pure time preference of individuals, $\mu$ is the death rate which is equal to the birth rate, $\Omega \in[0,1]$ is a constant and $\sigma$ is a coefficient of 
relative risk aversion such that the intertemporal elasticity of substitution is $1 / \sigma$. While the main implications of the Romer (1990) model carry over to this framework, Prettner (2009) shows that a decrease in mortality, which corresponds to population ageing, fosters economic growth. The reasons is that individuals who live longer, are more likely to postpone consumption into the future and increase their savings. Higher savings will decrease interest rates and consequently returns to R\&D investments accruing in the future are discounted less heavily. As a result, investments into $R \& D$ are more likely to pay off and an economy with an older population structure features faster per capita growth in the long-run. This approach abstracted from productivity differentials between younger and older workers as well as from considerations with respect to pension systems. Introducing these aspects could be promising for future research regarding the impacts of demographic change on economic development.

\subsection{Vertical Innovations}

In contrast to Romer (1990), technological progress is referred to as an increase in the quality of varieties in the Grossman and Helpman (1991) framework. It is assumed that there is a continuum of goods, whose quality can be improved infinitely via innovations by a factor of $\lambda$. These innovations are introduced by the firms who carry out in-house R\&D. The corresponding type of technological progress is referred to a vertical innovation. Research success - which positively depends on R\&D intensity - follows a Poisson Process with arrival rate $\tilde{\imath}$. Additionally, it is assumed that only the firm which produces the highest quality of a certain good is able to sell it. ${ }^{6}$ For these incumbents it is not optimal to carry out R\&D for the product line, where they are leaders, but rather to invest in innovations of another variety. The optimal research effort for each firm that is not yet the leader is indeterminate due to the constant returns to labour. Since all product lines yield the same profit, individual firms are indifferent which industry they should target with their R\&D efforts. Denoting aggregated R\&D efforts of all firms in one product line as $\imath$, the law of large numbers ensures that a fraction $\imath$ of all products in an economy are improved at each instant. The corresponding growth rate of per capita output is $g=\imath \log \lambda$.

Combining the Euler equation from the consumer's optimization problem with the expression for the profit flow of firms and imposing the market clearing condition that total labour must either be employed in $R \& D$ or in production leads to the following expression for optimal aggregate $R \& D$ intensity:

$$
\imath=\frac{\left(1-\frac{1}{\lambda}\right) L}{a_{I}}-\frac{\rho}{\lambda}
$$

where $L$ denotes the total size of the labour force which is again equivalent to the population size, $\rho$ is the discount rate of individuals and $a_{I}$ represents a firm's labour input coefficient for creating an innovation with probability $\tilde{\imath}$. Putting things together, the steady state per capita output growth rate can be written as

$$
g^{*}=\left[\frac{\left(1-\frac{1}{\lambda}\right) L}{a_{I}}-\frac{\rho}{\lambda}\right] \log \lambda
$$

which tells us that a decrease in the labour requirement for $\mathrm{R} \& \mathrm{D}$, an increase in the size of innova-

\footnotetext{
${ }^{6}$ To be precise: It is not only quality that matters, but the quality-adjusted price. Only the firm with highest quality of its output can charge a quality-adjusted price that allows for positive profits. If the firm with the second highest quality of its output wants to produce, it can charge a higher quality-adjusted price but then nobody would want to buy its good (Bertrand competition). It is optimal for the incumbent to charge exactly this price (limit price) because its profits would be lower if the price were also lower, while another firm would enter the market and thereby erode the profit of the incumbent, if the price were higher.
} 
tions and a decrease in the discount rate of individuals boosts growth. Moreover, the population size $L$ has a growth enhancing effect because a larger population ceteris paribus increases the number of scientists. Consequently, the main policy implication carries over from the Romer (1990) model. Subsidizing R\&D raises long-run per capita output growth because the R\&D sector could then attract more scientists. Population growth is not allowed because it would be inconsistent with a balanced growth path. In contrast, population ageing could be considered by following a similar strategy as in Prettner (2009) in case of the Romer (1990) model. This is on top of our research agenda.

Aghion and Howitt (1992) follow the same basic setup as Grossman and Helpman (1991) because they consider technological progress as an increase in quality of existing varieties. However, they do not assume a continuum of goods, but rather that there exists one intermediate input which is used to build final output according to the production function

$$
y=A F(x) .
$$

In this context $x$ is the intermediate input used for production, $A$ is a parameter that indicates the productivity of this intermediate input, i.e. it represents the technological frontier, and $F$ denotes a well behaved production function. Similarly to Grossman and Helpman (1991), only the firm with the highest quality level produces $x$. All other firms do not produce but they perform R\&D. Each innovation increases the quality of $x$, and the firm that introduces the innovation becomes the new incumbent, kicking out the former incumbent from it's monopoly position.

Innovations, whose size is denoted by $\gamma$, occur stochastically following a Poisson process with arrival rate $\lambda$. Furthermore, technological progress can be enhanced by allocating additional skilled labour to the research sector. With these assumptions, Aghion and Howitt (1992) derive the following average per capita growth rate in a stationary ${ }^{7}$ equilibrium:

$$
g^{*}=\lambda \phi(\hat{n}) \gamma
$$

where $\hat{n}$ is the number of skilled workers allocated to the research sector which is endogenously determined in equilibrium and $\phi$ is a function with constant returns describing productivity of researchers. The amount of skilled workers increases in the population size, the arrival rate and the size of innovations. However, it decreases if the interest rate increases because then firms would have to discount their future profits more heavily, thus they would perform less R\&D and consequently lower their demand for skilled workers.

Altogether this ensures that the skilled labour endowment, which increases in the population size, has a positive impact on long-run per capita output growth. If the growth rate should be increased, the policy implications are similar to the Romer (1990) model, in particular to subsidize R\&D. Again, population growth is ruled out because it is inconsistent with balanced growth. Population ageing is not considered in Aghion and Howitt (1992) and we expect that it would be very hard to implement because of the complexity of the model.

\footnotetext{
${ }^{7}$ Equilibria with cyclical growth or even with no-growth are possible in this setup. For details see Aghion and Howitt (1992).
} 


\section{Semi-Endogenous Growth Models}

All endogenous growth models considered so far exhibit a scale effect in the sense that economies with larger populations should grow faster. Furthermore, they suggest that an increase in the number of scientists would lead to acceleration of technological progress and thus per capita output growth. Jones (1995) argues that these predictions are not supported by empirical evidence. He proposes a scale invariant model by relying on the Romer (1990) framework but changing equation (12) to

$$
\frac{\dot{A}}{A}=\delta \frac{L_{A}^{\lambda}}{A^{1-\phi}},
$$

where $0<\lambda \leq 1$ accounts for the fact that different researchers may work on similar problems and therefore create the same result twice, i.e. there is a redundancy in $R \& D$ if $\lambda<1$, and $\phi$ is a parameter measuring the strengths of intertemporal knowledge spillovers. If $\phi<1$ these spillovers are insufficiently small to prevent innovations from becoming more and more difficult as the technological frontier evolves. With these assumptions, Jones (1995) is able to derive the per capita growth rate of the model economy in the steady state as

$$
g_{y}^{*}=\frac{\lambda n}{1-\phi}
$$

with $n$ being the growth rate of the population and hence also of the labour force. Consistent with empirical findings, there are no scale effects in the long run, so the size of the labour force does not matter. However, the growth rate of the labour force $n$, which is required to be positive, is decisive in determining per capita growth. The faster the population grows, the higher is the long-run per capita growth rate of the economy. Since the steady state growth rate only depends on parameter values, there is no way for policy-makers to increase growth in the steady state which is the reason why these models are called semi-endogenous.

Several extensions of the original Jones (1995) model have been suggested in the literature. Kortum (1997) provides a microfoundation for equation (18), while the model of Segerström (1999) addresses vertical innovations and gets rid of the scale effect in this type of models. As regards the role of population growth and policy implications, they carry over from Jones (1995).

As regards population ageing in the Jones (1995) case, Prettner (2009) abandons the representative agent assumption and introduces an OLG structure according to Buiter (1988). Each individual faces a constant age independent risk of death $\mu$. To be consistent with the central assumption of the Jones (1995) approach, the birth rate $\beta$ is assumed to be larger than the death rate such that the population grows at the positive rate $n=\beta-\mu$. In contrast to Jones (1995), the model by Prettner (2009) allows to address the different impacts of changing fertility and changing longevity on economic growth. The following expression for the steady state growth rate $g_{y}$ can be derived ${ }^{8}$

$$
g_{y}^{*}=\frac{\beta-\mu}{1-\phi},
$$

where $\phi \in[0,1]$ measures intertemporal knowledge spillovers. The central results of the Jones (1995) model carry over to this framework but now it is possible to disentangle population growth between changes in longevity and changes in fertility. While a decrease in fertility - associated

\footnotetext{
${ }^{8}$ Note that this expression does not allow for duplication in the research process as compared to the standard Jones (1995) model. However, this does not affect the central results.
} 
with population ageing - lowers population growth and thereby the steady state per capita growth rate of the economy, the converse holds true for decreasing mortality - associated with an increase in population growth. Consequently, while population ageing has been beneficial for long-run economic growth in the Romer (1990) case, it hampers economic development in the Jones (1995) framework.

A model that allows for a negative correlation between population growth and economic growth is presented in Dalgaard and Kreiner (2001). This model builds on the Romer (1990) approach to set up a scale invariant growth model by endogenizing human capital accumulation. The production function

$$
Y_{t}=\left(\frac{H_{t}}{A_{t}}\right)^{\alpha} \int_{j=0}^{A_{t}} x_{j t}^{\gamma} d j Z^{1-\alpha-\gamma}
$$

is used, where $H_{t}=h_{t} L_{t}$ denotes the stock of human capital, with $h_{t}$ being average quality of labour and $L_{t}$ referring to the size of the labour force, $A_{t}$ is the technological frontier, $x_{j t}$ represents specialized inputs, $Z$ refers to a production factor of fixed supply, which is normalized to one, $\alpha$ represents the human capital share of final output, $\gamma$ the intermediate input share, and $1-\alpha-\gamma$ the fixed input factor share. The first term on the right hand side ensures that, as technology gets more and more complex, the importance of human capital in final goods production increases.

Households have to decide how to allocate their income between consumption and investment, where the latter is divided into human capital investments, whose return are higher future wages, and investments into new ideas, whose return are interest payments on the invested capital. Additionally, it is assumed that governments can subsidize both investments. They finance these subsidies by means of lump sum taxes.

Altogether their model structure leads to laws of motion for the technological level and the average quality of labour as

$$
\begin{aligned}
\dot{A}_{t} & =I_{t}^{A}, \\
\dot{h_{t}} & =\frac{I_{t}^{H}}{L_{t}}-n h_{t},
\end{aligned}
$$

where $I_{t}^{A}$ is the fraction of household's income invested in technology, $I_{t}^{H}$ is the fraction of household's income invested in human capital and $n$ is the population growth rate. The last term in equation (23) refers to congestion, meaning that it becomes more and more difficult to sustain a high average human capital level if the number of people to be educated increases. With these assumptions, Dalgaard and Kreiner (2001) are able to derive per capita output growth in the steady state as

$$
g_{y}^{*}=\frac{1}{\epsilon}\left(\left(1+\tau^{H}\right) \alpha\left(\frac{\gamma(1-\gamma)}{\alpha} \frac{1+\tau^{A}}{1+\tau^{H}}\right)^{\frac{1-\alpha-\gamma}{1-\gamma}} \gamma^{\frac{2 \gamma}{1-\gamma}}-\theta-n\right),
$$

where $\tau^{H}$ are subsidies for human capital investments, $\tau^{A}$ are subsidies for technological investments and $\theta$ is an individuals' discount rate. Equation (24) states that per capita output growth positively depends on investment in human capital, investment in technology, and the intermediate input share, whereas it negatively depends on the individual's discount rate and, remarkably, the growth rate of the population. ${ }^{9}$

To summarize, the following conclusions can be drawn: Long-run per capita output growth

\footnotetext{
${ }^{9}$ This result is, however, not robust against respecifications of the instantaneous utility function. See Dalgaard and Kreiner (2001) for details.
} 
is not affected by changes in the population size, but population growth has a negative impact under the utility function used in the model. In contrast to standard semi-endogenous growth models, policy-makers are able to intervene via changes in subsidies for human capital as well as technological investments. Population ageing is not considered in the Dalgaard and Kreiner (2001) model but could again be introduced as described in Prettner (2009).

\section{Growth Models with Horizontal and Vertical Innovations}

One shortcoming of semi-endogenous growth models in the spirit of Jones (1995) is that they result in long-run economic growth relying on parameter values which cannot be affected by economic policy. The model of Peretto (1998) derives a long-run growth rate that can be influenced by economic policy but nevertheless gets rid of the scale effect by integrating horizontal and vertical innovations. This is done by assuming that incumbents carry out quality improving and thus productivity enhancing in-house R\&D, whereas new firms, who continuously enter markets, perform horizontal innovations by introducing new products. As a consequence, per capita growth of the economy, measured increasing consumption of an aggregate good consisting of different varieties, has three dimensions:

$$
g \equiv \frac{\dot{C}}{C}=g_{v}+\frac{1}{\epsilon-1} g_{h}+x,
$$

where $\epsilon$ refers to the elasticity of substitution between different product varieties.

1. Growth via gains in efficiency (vertical innovations):

$$
g_{v} \equiv \frac{\theta \dot{Z}}{Z}=\frac{\theta \alpha L_{Z}}{N},
$$

where $g_{v}$ represents productivity growth, $\theta$ is the elasticity of a unit cost reduction of the specific variety with respect to quality improvements, $Z$ refers to the stock of knowledge, $\alpha$ is productivity of labour employed in R\&D which is in turn denoted by $L_{Z}$, and $N$ represents the number of firms in the economy.

2. Growth via increases in the number of varieties, i.e. increases in the number of firms that enter the market (horizontal innovation):

$$
g_{h} \equiv \frac{\dot{N}}{N}=\frac{\beta L_{N}}{N},
$$

where $g_{h}$ is the growth rate of the number of firms ${ }^{10}, \beta$ refers to the productivity of labour in horizontal innovation, and $L_{N}$ is the aggregate amount of workers devoted to start-up firms.

3. Growth via increases in production:

$$
x \equiv \frac{\dot{L}_{X}}{L_{X}},
$$

with $x$ referring to production growth and $L_{X}$ to labour devoted to production.

While a scale effect is present in quality improving $R \& D$, there is no effect of a larger population size on the long-run rate of entry. This is the case because Peretto (1998) assumes that knowledge

\footnotetext{
${ }^{10}$ Peretto (1998) uses $n$ to denote growth in the number of firms. To be consistent with the other parts of the survey, where $n$ refers to population growth, we changed it to $g_{h}$.
} 
spillovers in horizontal innovation are insufficiently low to generate long-run growth, hence only changes in the population growth rate are able to effect steady state entry. However, the scale effect present in quality improving $R \& D$ vanishes in the long-run steady state equilibrium because an increase in the population size not only spurs vertical innovations but also horizontal innovations (firm entry) and therefore in-house $R \& D$ resources have to be divided between more firms. This eventually leads to a rate of quality improvements that is equivalent to the original rate before the increase in the population size.

In the steady state, where production and the number of varieties grow at the same rate $g_{h}=x=n$ with $n$ denoting population growth, this expression reduces to

$$
g^{*}=\frac{\epsilon}{\epsilon-1} n+g_{v}
$$

Finally, after solving for the general equilibrium, Peretto (1998) arrives at the following expression

$$
g^{*}=\frac{\epsilon n}{\epsilon-1}+\frac{\theta \rho[\alpha \theta(\epsilon-1)-\beta]}{\beta[1-\theta(\epsilon-1)]},
$$

where $\rho$ is the discount rate of individuals. By inspection of equation (30), it is clear that there are no scale effects, but that population growth positively affects steady state per capita growth like in semi-endogenous growth models. However, an increase in population growth has ambiguous effects on per capita growth of the economy in the medium-run because on the one hand, it increases entry (horizontal innovation) and output growth but on the other hand the increase in the number of firms slows down productivity growth (vertical innovations) as evident from equation (26). An increase in the population size leads to temporarily faster per capita growth but eventually the economy converges back to the original steady state growth rate. Population ageing is not analysed in this model but could again be introduced as described in Prettner (2009).

Peretto (1998) also analyses the effects of governmental subsidies on medium- and long-run economic growth perspectives. He thereby considers five different cases:

1. An increase in R\&D subsidies for incumbents leads to an increase in per capita growth in the long-run, since productivity growth (vertical innovation) increases, and entry (horizontal innovation) as well as production growth stay the same.

2. An increase in $R \& D$ subsidies for entrants deceases per capita growth in the long-run because labour is shifted away from R\&D of quality improving firms (vertical innovation) to entrants (horizontal innovation). Due to the specification or research spillovers, this decreases productivity growth permanently, while entry is just temporarily boosted and so per capita growth decreases in the long run.

3. A broad R\&D subsidy that is granted to incumbents as well as entrants does not change longrun per capita growth because the positive and negative effects exactly offset each other.

4. A government tax on firm profits net of $R \& D$ works as if ownership of a firm and therefore entry is taxed. This means that it has the reverse effects as compared to an increase in the subsidy to entrants.

5. A government tax on firm profits gross of R\&D expenditures works like a reduction of the market size and has transitory effects only. 
Several variations and extensions of the Peretto (1998) model exist in the literature. These include the model of Young (1998) who does not determine the frequency of innovations endogenously but rather their size as well as the model of Howitt (1999) who introduces vertical innovations into the Aghion and Howitt (1992) framework and shows that in this case also broad subsidies that are not only restricted to horizontal innovation have positive effects on economic growth in the steady state. A more general model that allows for stochastic growth and thus uncertainty is presented by Dinopoulos and Thompson (1998).

An interesting paper that takes into account the endogenous demographic structure is Connolly and Peretto (2003). They use the model of horizontal and vertical innovations to endogenize fertility as in the Becker and Barro (1988) model. This provides them with more realistic demographic structures which allows them to perform policy experiments with respect to changes in reproduction costs and exogenously given mortality rates. Connolly and Peretto (2003) derive the steady state expression for per capita growth as ${ }^{11}$ :

$$
g=(\chi-1) n+\theta z
$$

where $\chi$ denotes the research spillovers from horizontal innovations, $n$ denotes population growth which pins down firm entry in the long-run, $\theta$ is the elasticity of production with respect to quality improvement, whose rate is denoted by $z$.

Obviously, scale effects do not occur in this case. However, as long as research spillovers from horizontal innovations are larger than one, population growth positively affects per capita output growth. If this is not the case, population growth can even have negative impacts. Connolly and Peretto (2003) restrict their attention to the former case.

With respect to innovations, there are three possible policies to be implemented, whose effects are investigated numerically by Connolly and Peretto (2003). First, a subsidy for vertical innovations positively affects medium- as well as long-run per capita output growth. Second, a subsidy for horizontal innovations positively affects medium-run but negatively affects long-run per capita output growth, and third, symmetric positive subsidies for both types of research positively affect medium-run per capita output growth, whereas long-run per capita output growth remains unchanged.

A further interesting paper that relates to demographic change via endogenous human capital accumulation is Strulik (2005). He builds on the models with horizontal and vertical innovations and implements endogenous educational decisions of households. Aggregate human capital is obtained by multiplying the population size with the per capita human capital created by education. It is assumed that newborns enter the economy without education and therefore faster population growth hampers aggregate human capital growth. Eventually, the growth rate of per capita output in the steady state, $g_{y}^{*}$, can be written as

$$
g_{y}^{*}=\frac{\xi-\delta-\rho}{\theta-1}\left(1-\frac{1}{\theta+\phi}\right)+\frac{1}{\theta-1}\left[m-\frac{\theta-(1-m)}{\theta+\phi}\right] n,
$$

where $\xi$ is the productivity of education in creating human capital, $\delta$ is the rate of knowledge depreciation, $\rho$ is the discount rate of individuals, $\theta$ measures relative risk aversion in the CRRA instantaneous utility function and determines the intertemporal elasticity of substitution as $\frac{1}{\theta}, \phi$

\footnotetext{
${ }^{11}$ In doing so they restrict their parameter values such that both types of innovations have to occur in equilibrium. For details see Connolly and Peretto (2003).
} 
is a collection of parameters which can be shown to exceed 1 and negatively depend on competition captured by the elasticity of substitution between intermediate input varieties, $\sigma, m$ governs altruism, i.e. for $m=1$ the utility function is Benthamite and households maximize utility of all members of the dynasty, whereas for $m=0$ the utility function is Millian and households just maximize their own per capita utility and finally, $n$ denotes population growth. It is immediately clear that the steady state per capita growth rate of the economy decreases in impatience of households and depreciation of human capital and it increases in productivity of education. While the population size does not matter for the steady state growth rate, the effects of population growth are ambiguous, except for two knife-edge parameter assumptions. If $m=0$ (Millian preferences) the only effect of population growth on economic growth is the human capital dilution effect which occurs because individuals enter the economy uneducated and therefore population growth reduces per capita human capital. In this case population growth negatively impacts upon per capita output growth in the steady state. In contrast, if $m=1$ (Benthamite preferences), there is the additional effect that population growth reduces the effective rate of time preference. In this case population growth positively impacts upon per capita output growth in the steady state.

Altogether the standard way in which policy-makers can influence economic growth, namely through R\&D subsidies, is not applicable here. However, increases in efficiency of education as well as more competition would be able to spur economic development.

\section{Conclusions}

Low birth rates and increasing survival to higher ages will shape the future demographic structure in most industrialized countries. Whether - through which channels and in which extent - those demographic developments will impinge on economic growth is not yet clear. One approach we followed in this paper is to rely on formal economic growth models and study the relationship between demographic developments and economic growth prospects. More specifically, the aim of our paper was to review selected economic growth models (focusing on endogenous growth models) and illustrate their predictions on the interrelationship between demographic development and economic growth. In particular, we reviewed extensions of those models that explicitly allow for population ageing if such frameworks were available. In addition, we addressed the policy implications of the models under considerations.

We may draw several conclusions from our review. (a) While there have recently been attempts to include a more realistic age structure and more realistic models of survival into exogenous growth models, there is still scope for further research on this topic in endogenous growth models. (b) Whether population growth or population size foster or hamper economic growth strongly depends on the modelling framework. In models of exogenous growth the relation between population growth and economic growth is negative. Endogenous growth models of the first generation (section

3) yield a positive association between population size and economic growth. In semi-endogenous growth models (section 4) population growth, instead of population size, positively influences economic growth. In our view, most promising are recent semi-endogenous growth models (see Dalgaard and Kreiner, 2001; Strulik, 2005) that allow for a negative association of population growth and economic growth. With respect to models that explicitly account for population ageing we again find dependence of the results on the underlying assumptions. Population ageing can have positive impacts on economic growth if it triggers additional savings or investments into R\&D while leaving the size of the workforce unchanged (see Futagami and Nakajima, 2001; 
Prettner, 2009), it can also have negative impacts if pension schemes are designed such that the size of the workforce decreases relative to the amount of retirees (see Futagami et al., 2002; Gruescu, 2007 ) or if population ageing is driven by declines in fertility that also slow down population growth (see Prettner, 2009). (d) In summary, our review suggests that R\&D subsidies are effective to promote long-run economic growth in endogenous growth models, while they are ineffective in the steady state of semi-endogenous growth models. In frameworks that integrate horizontal and vertical $R \& D$ it is in general the case that subsidies to horizontal innovation only increase growth in the medium run, while subsidies to vertical innovation are able to spur economic growth even in the long run. 


\section{References}

Aghion, P. and Howitt, P. (1992). A model of growth through creative destruction. Econometrica, Vol. 60(No. 2):323-351.

Alogoskoufis, G. and van der Ploeg, F. (1990). Endogenous growth and overlapping generations. Discussion Paper 9072, CentER, Tilburg University.

Auerbach, A. J. and Kotlikoff, L. J. (1987). Dynamic Fiscal Policy. Cambridge University Press.

Becker, G. S. (1960). Demographic and Economic Change in Developed Countries, chapter An economic analysis of fertility, pages 209-231. Princeton University Press, Princeton.

Becker, G. S. and Barro, R. J. (1988). A reformulation of the economic theory of fertility. The Quarterly Journal of Economics, Vol. 103(No. 1):1-25.

Blanchard, O. J. (1985). Debt, deficits and finite horizons. Journal of Political Economy, Vol. 93(No. 2):223-247.

Bloom, D. E., Canning, D., and Fink, G. (2008). Population Aging and Economic Growth. The World Bank. Commission on Growth and Development. Working Paper 32.

Bloom, D. E., Canning, D., and Fink, G. (2010). The Graying of Global Population and its Macroeconomic Consequences. The WDA-HSG Discussion Paper Series on Demographic Issues No. $2010 / 4$.

Bommier, A. and Lee, R. D. (2003). Overlapping generations models with realistic demography. Journal of Population Economics, Vol. 16(No. 1):135-160.

Boucekkine, R., de La Croix, D., and Licandro, O. (2002). Vintage human capital, demographic trends, and endogenous growth. Journal of Economic Theory, Vol. 104(No. 2):340375.

Brander, J. A. and Dowrick, S. (1994). The role of fertility and population in economic growth. Journal of Population Economics, Vol 7(No 1):1-25.

Buiter, W. H. (1988). Death, birth, productivity growth and debt neutrality. The Economic Journal, Vol. 98:179-293.

Cass, D. (1965). Optimum growth in an aggregative model of capital accumulation. The Review of Economic Studies, Vol. 32(No. 3):233-240.

Connolly, M. and Peretto, P. (2003). Industry and the family: Two engines of growth. Journal of Economic Growth, Vol. 8:115-148.

d'Albis, H. (2007). Demographic structure and capital accumulation. Journal of Economic Theory, Vol 132(No 1):411434.

Dalgaard, C. and Kreiner, C. (2001). Is declining productivity inevitable? Journal of Economic Growth, Vol. 6(No. 3):187-203.

de la Croix, D. and Licandro, O. (1999). Life expectancy and endogenous growth. Economics Letters, Vol. 65(No. 2):255263. 
Diamond, P. A. (1965). National debt in a neoclassical growth model. American Economic Review, Vol. 55(No. 5):1126-1150.

Dinopoulos, E. and Thompson, P. (1998). Schumpetarian growth without scale effects. Journal of Economic Growth, Vol. 3:313-335.

Eurostat (2009). Eurostat yearbook 2009. Office for Official Publications of the European Communities.

Futagami, K., Iwaisako, T., and Nakajima, T. (2002). Technological innovation, productivity, and economic growth in aging societies. In Siebert, H., editor, Economic Policy for Aging Societies, pages 163-173. Springer.

Futagami, K. and Nakajima, T. (2001). Population aging and economic growth. Journal of Macroeconomics, Vol. 23(No. 1):31-44.

Grafenhofer, D., Jaag, C., Keuschnigg, C., and Keuschnigg, M. (2006). Probabilistic aging. CESifo Working Paper No. 1680. pages 1-36.

Grossman, G. M. and Helpman, E. (1991). Quality ladders in the theory of economic growth. Review of Economic Studies, Vol. 58(No. 1):43-61.

Gruescu, S. (2007). Population Ageing and Economic Growth. Physica-Verlag.

Heijdra, B. J. (2009). Foundations of Modern Macroeconomics. Oxford University Press.

Heijdra, B. J. and Romp, W. E. (2006). Ageing and growth in the small open economy. Working Paper 1740, CESifo, München.

Heijdra, B. J. and Romp, W. E. (2007). Retirement, pensions, and ageing. working paper 1974, CESifo, München.

Horvath, G. T. (2007). Modeling demographics and life-cycle details in models of overlapping generations. Master's thesis, University of Vienna.

Howitt, P. (1999). Steady endogenous growth with population and r \& d inputs growing. Journal of Political Economy, Vol. 107(No. 4):715- 730.

Jones, C. I. (1995). R\&D-based models of economic growth. Journal of Political Economy, Vol. 103(No. 4):759-783.

Kelley, A. C. and Schmidt, R. M. (1995). Aggregate population and economic growth correlations: the role of the components of demographic change. Demography, Vol 32(No. 4):543555.

Koopmans, T. C. (1965). On the concept of optimal economic growth. In The Econometric Approach to Development Planning. Amsterdam: North Holland.

Kortum, S. (1997). Research, patenting and technological change. Econometrica, Vol. 65(No. $6): 1389-1419$.

Li, Q. and Tuljapurkar, S. (2004). Life, death and the economy: Mortality change in overlappinggenerations model. michigan retirement research center. working papers. wp072. 
Lucas, R. E. (1988). On the mechanics of economic development. Journal of Monetary Economics, 22:3-42.

Peretto, P. F. (1998). Technological change and population growth. Journal of Economic Growth, Vol. 3(No. 4):283-311.

Prettner, K. (2009). Population ageing and endogenous economic growth. Working Paper, Vienna Institute of Demography.

Prettner, K. and Prskawetz, A. (2010). Decreasing fertility, economic growth and the intergenerational wage gap. Empirica, forthcoming, Vol. 37(No. 2):197-214.

Ramsey, F. P. (1928). A mathematical theory of saving. The Economic Journal, Vol. 38(No. 152):543-559.

Romer, P. (1986). Increasing returns and long-run growth. Journal of Political Economy, Vol. 94(No. 5):1002-1037.

Romer, P. (1990). Endogenous technological change. Journal of Political Economy, 98(No. 5):71102.

Saint-Paul, G. (1992). Fiscal policy in an endogenous growth model. Quarterly Journal of Economics, Vol. 107(No 4).

Samuelson, P. A. (1958). An exact consumption-loan model of interest with or without the social contrivance of money. Journal of Political Economy, Vol. 66(No. 6).

Segerström, P. S. (1999). Endogenous growth without scale effects. American Economic Review, Vol 88.(No. 5):1290-1310.

Solow, R. M. (1956). A contribution to the theory of economic growth. The Quarterly Journal of Economics, Vol. 70(No. 1):65-94.

Strulik, H. (2005). The role of human capital and population growth in R\&D-based models of economic growth. Review of International Economics, Vol. 13(No. 1):129-145.

United Nations (2007). World population prospects: The 2006 revision. Url: http://www.un.org/esa/population/publications/wpp2006/english.pdf.

Yaari, M. E. (1965). Uncertain lifetime, life insurance and the theory of the consumer. The Review of Economic Studies, Vol. 32(No. 2):137-150.

Young, A. (1998). Growth without scale effects. Journal of Political Economy, Vol. 106(No. $5): 41-63$. 


\section{VIENNA INSTITUTE OF DEMOGRAPHY}

\section{Working Papers}

Flandorfer, Priska, Christian Wegner, and Isabella Buber, Gender Roles and Smoking Behaviour, VID Working Paper 07/2010.

Barakat, Bilal, Johannes Holler, Klaus Prettner, and Julia Schuster, The Impact of the Economic Crisis on Labour and Education in Europe, VID Working Paper 06/2010.

Grafeneder-Weissteiner, Theresa and Klaus Prettner, Agglomeration Processes in Ageing Societies, VID Working Paper 05/2010.

Buber, Isabella, Parity-specific weights for the Austrian Generations and Gender Survey, VID Working Paper 04/2010.

Testa, Maria Rita, She wants, he wants: Couple's childbearing desires in Austria, VID Working Paper 03/2010.

Buber, Isabella, Wissenschaftlerinnen in Österreich - Zusatzerhebung im Rahmen des GGS.Dokumentation der Datenerhebung und deskriptive Ergebnisse, VID Working Paper 02/2010.

Kuhn, Michael, Stefan Wrzaczek, Alexia Prskawetz, and Gustav Feichtinger, Externalities in a Life-Cycle Model with Endogenous Survival, VID Working Paper $01 / 2010$.

Prettner, Klaus, Population Ageing and Endogenous Economic Growth, VID Working Paper 08/2009.

Št’astná, Anna and Tomáš Sobotka, Changing Parental Leave and Shifts in Second and Third-Birth Rates in Austria, VID Working Paper 07/2009.

Prettner, Klaus and Alexia Prskawetz, Decreasing Fertility, Economic Growth and the Intergenerational Wage Gap, VID Working Paper 06/2009.

Wegner, Christian and Marc Luy, Determinants of General Health and Specific Diseases of Elderly Women and Men: A Longitudinal Analysis for Western and Eastern Germany, VID Working Paper 05/2009.

Wrzaczek, Stefan, Michael Kuhn, Alexia Prskawetz, and Gustav Feichtinger, The Reproductive Value in Distributed Optimal Control Models, VID Working Paper 04/2009.

The Vienna Institute of Demography Working Paper Series receives only limited review. Views or opinions expressed herein are entirely those of the authors. 